\title{
ESPECIALIZAC̣ÃO DA PECUÁRIA NOS MUNICÍPIOS DE MATO GROSSO DO SUL
}

\section{LIVESTOCK SPECIALIZATION IN THE MUNICIPALITIES OF MATO GROSSO DO SUL}

\author{
Daniela Vasconcelos de Oliveira ${ }^{1}$ \\ Mayra Bitencourt Fagundes ${ }^{2}$ \\ Daniela Teixeira Dias ${ }^{3}$
}

\begin{abstract}
Resumo
Este artigo tem como objetivo analisar o nível de concentração de emprego das principais atividades pecuárias (bovinocultura de corte, avicultura e suinocultura) do Mato Grosso do Sul, levando em consideração aspectos relevantes do desenvolvimento regional dessas atividades. Para tanto, foi utilizado o método quantitativo na mensuração dos indicadores de especialização, que compõem o Índice de Concentração Normalizado (ICN). Para fundamentar essas estimativas, as discussões voltadas à economia regional e aos indicadores de desenvolvimento subsidiaram a análise teórica e histórica dos índices utilizados. Dentre os principais resultados encontrados, houve destaque aos municípios que apresentaram o maior ICN para empregos formais: Santa Rita do Pardo, Bataguassu, Sidrolândia, Itaquiraí, São Gabriel do Oeste, Jateí e Dourados. Vale ressaltar ainda que, diante dessas concentrações, buscou-se compreender a interação entre as atividades, desde o fornecimento de insumos até o escoamento da produção, bem como as distribuições geográficas e suas contribuições para o desenvolvimento local dos municípios.
\end{abstract}

Palavras-chave: Agronegócio. Economia Regional. Bovinocultura. Avicultura. Suinocultura.

\footnotetext{
Abstract

This article aims to analyze the level of employment concentration of the main livestock activities (beef cattle, poultry and swine) in Mato Grosso do Sul, taking into account relevant aspects of the regional development of these activities. For that, the quantitative method was used to measure the specialization indicators, which make up the Normalized Concentration Index (ICN). To support

${ }^{1}$ Mestre em Agronegócios pela Universidade de Brasília (UNB) e Pesquisadora do Programa de Pesquisa para o Desenvolvimento Nacional (PNPD) na DIRUR-IPEA. Brasília - DF, Brasil. E-mail: daniela.vasconcelos12@gmail.com ${ }^{2}$ Doutora em Economia Aplicada pela Universidade Federal de Viçosa (UFV) e professora Adjunta da Universidade Federal de Mato Grosso (UFMS), Campo Grande - MS, Brasil. E-mail: bitencourtmayra@gmail.com.

${ }^{3}$ Mestre em Administração de Agronegócios pela Universidade Federal do Mato Grosso do Sul (UFMS), Campo

Grande -MS e Gestora do Instituto de Pesquisa e Desenvolvimento FECOMÉRCIO - IPF/MS. E-mail:

danielateixeiradias@hotmail.com.
} 
these estimates, discussions on regional economics and development indicators supported the theoretical and historical analysis of the indices used. Among the main results found, the municipalities with the highest ICN for formal jobs were highlighted: Santa Rita do Pardo, Bataguassu, Sidrolândia, Itaquiraí, São Gabriel do Oeste, Jateí and Dourados. It is also worth mentioning that, in view of these concentrations, we sought to understand the interaction between activities, from the supply of inputs to the flow of production, as well as geographic distributions and their contributions to the local development of municipalities.

Keywords: Agribusiness. Regional Economy. Cattle. Poultry. Pig Industry.

\section{Introdução}

O agronegócio vem se destacando ao longo dos anos, pela sua contribuição à economia brasileira, bem como pelos avanços da produtividade e do PIB. Segundo os dados do CEPEA (2018), esse setor não só impulsionou o PIB, como também contribuiu para o controle da inflação no país. Somente em 2017, o PIB (a preços constantes) do agronegócio cresceu 7,6\%.

Dentre as atividades que compõem o agronegócio, há destaque para a pecuária, com ênfase na bovinocultura de corte, na suinocultura e na avicultura. Isso, inclusive, no cenário mundial. Mas, assim como as demais atividades econômicas, a pecuária possui momentos mais pujantes e outros mais contraídos.

Desse modo, conforme o Boletim PIB do agronegócio do CEPEA (2017), a bovinocultura de corte enfrentou situações adversas entre os anos de 2015 e 2016. Período esse marcado pelo recuo de 2,8\% no faturamento dos frigoríficos, em função, principalmente, da redução de consumo do mercado interno e dos insumos (-2,93\%) utilizados na produção. Em 2017, a pecuária retomou seu crescimento e em 2018 foi possível verificar a recuperação dos preços da arroba do boi gordo, motivada pelo melhor desempenho das exportações (ABIEC, 2017; VIEIRA FILHO e SOUZA JÚNIOR, 2018).

Já no que diz respeito ao mercado da suinocultura, observam-se algumas incertezas, em meio à demanda final, preços e aquisição de novos lotes de animais, mas também oportunidades. Assim como a avicultura, que, em 2017, teve um enfraquecimento do seu mercado e que, em 2018, retomou sua produtividade e deteve aumento dos preços de seus produtos, dado o encarecimento do milho e do farelo de soja, os principais insumos utilizados por esse setor.

Em abril de 2018, a União Europeia declarou embargo às carnes de frango de 20 estabelecimentos brasileiros. Dentre esses estabelecimentos, havia dois frigoríficos do Mato Grosso do Sul, a BRF S.A. (Dourados) e Bello Alimentos Ltda. (Itaquiraí). Vale destacar que as exportações de carne de frango para a UE correspondiam a 35\% das exportações brasileiras e o embargo prejudicou os estímulos aos investimentos que já estavam sendo aplicados no setor (VALOR ECONÔMICO, 2018; PORTAL DO GOVERNO DO MS, 2018).

Apesar desse cenário, de altas e baixas para a pecuária, na economia nacional, o mercado de trabalho do agronegócio se manteve, praticamente, estável, quando considerados os dados de 2018, em relação aos de 2016, em que houve uma discreta redução de 1,6\% do número de pessoas ocupadas, passando de 18,53 milhões para 18,24 milhões de pessoas (CEPEA, 2018).

Como no Brasil, no Mato Grosso do Sul, a pecuária se destaca como uma importante atividade econômica, tanto pela vocação natural pré-existente voltada às extensões de terra e histórico de desenvolvimento da atividade, quanto pelo fomento industrial realizado pelo governo estadual e pelas condições exógenas favoráveis, direcionadas à distribuição geográfica, ou mesmo ao fomento das atividades provedoras de insumos (FAMASUL, 2017).

De acordo com a SEMAGRO (2015), o MS vem se destacando como um estado fundamental para a produção de matéria-prima para a pecuária, decorrente da agroindustrialização introduzida nos anos de 1980. A modernização do setor primário proporcionou ao estado, ao longo dos anos, uma maior capitalização do produtor e, indiretamente, a ampliação das oportunidades de emprego e renda.

Na pecuária, as questões voltadas ao emprego ganharam repercussão, principalmente diante da necessidade de tecnificação para ampliar a produtividade e os ganhos SEMAGRO (2015). Por isso, entender como está o nível de empregabilidade e de concentração de emprego pode ser um 
importante instrumento tanto para os produtores rurais, quanto para a esfera pública, na definição de incentivos e investimentos que possam ser necessários ao avanço do desenvolvimento regional.

Isso porque há diversas abordagens no que tange ao desenvolvimento regional, mas correntes mais contemporâneas de pensamento têm considerado as questões sociais, como aquelas referentes à mão-de-obra, qualificação, valorização do capital humano, fatores locacionais, insumos e de aglomeração como importantes para a economia regional (MYRDAL, 1957; HIRSCHMAN, 1958).

Considerando a relevância das atividades pecuárias para o estado, como também para o estímulo indireto de outros setores e da economia nacional, ao mesmo tempo em que há a preocupação com a geração de emprego e renda, diante da modernização do campo, este estudo buscou responder ao seguinte problema de pesquisa: quais municípios de Mato Grosso do Sul têm maior concentração de emprego formal nas atividades pecuárias?

Diante dessa problemática, o objetivo geral consistiu em analisar o nível de concentração do emprego das atividades pecuárias (bovinocultura de corte, avicultura e suinocultura) de Mato Grosso do Sul, considerando os aspectos relevantes para o desenvolvimento regional das atividades nos municípios em que se destacarem.

Para tanto, utilizou-se o método quantitativo, a partir da estimativa do Índice de Concentração Normalizado (ICN), da análise multivariada e de cálculos dos indicadores de especialização: Quociente Locacional (QL), Hirschman e Herfindahl Modificado (IHHM) e Índice de Participação Relativa (PR).

Este estudo se demonstra relevante no âmbito acadêmico, na identificação de regióes promissoras para incentivo de políticas públicas e de projetos de desenvolvimento regional, visando a um maior progresso da pecuária, considerando a importância do emprego para o estado.

\section{Revisão de Literatura}

\section{Economia Regional: Viés da Aglomeração e do Desenvolvimento Territorial}

A economia regional não tem uma abordagem teórica única e, sim, visões diversas que têm como objetivo, absorver a complexidade dos acontecimentos econômicos no espaço ou território (MONASTÉRIO; CAVALCANTE, 2011). Em função dessa multiplicidade de abordagens, Monastério e Cavalcante (2011) desenvolveram um estudo sobre esse assunto, que identificou e sistematizou a produção teórica direcionada ao debate acerca dos espaços territoriais inseridos nos limites nacionais, em que houvesse a possibilidade de intervenção e levantamento de informações individualizadas.

Por esse estudo, verificou-se que, até o século XX, a produção teórica inserida na economia regional, era caracterizada por dois grandes blocos teóricos. Sendo o primeiro, composto por teorias clássicas da localização, em que foram visualizados autores como Von Thünen (1826) e Isard (1956). Já o segundo bloco foi direcionado ao conjunto de teorias sobre o desenvolvimento regional, com ênfase nos fatores de aglomeração, que foram tratados nas análises de Perroux (1955), Myrdal (1957), Hirschman (1958) e North (1959). ${ }^{4}$

$\mathrm{Na}$ teoria clássica, as discussões sobre economia regional foram pautadas nos custos de transporte, para a determinação da localização ótima das atividades econômicas, mas foram desconsiderados os efeitos externos resultantes das aglomerações das atividades e o trade-off (escolhas) entre os ganhos de escala e dos custos de transporte.

Von Thünen (1826) buscava analisar qual seria o padrão de ocupação dos espaços geográficos, baseando-se nas premissas de que o terreno é homogêneo, os preços dos produtos são determinados na região, não existe monopólio e os agentes são tomadores de preços. Em anos posteriores, os estudos e teorias evoluíram.

Isard (1956), então, escreveu sobre Location and Space Economy (Localização e Economia do Espaço). Nesse estudo, o autor acrescentou noções sobre a otimização dos pontos para fixação de indústrias, localização das atividades econômicas, organização e estruturação do espaço, interações espaciais e o desenvolvimento regional, nas análises de economia regional.

De acordo com Monastério e Cavalcante (2011), a teoria de desenvolvimento regional com ênfase nos fatores de aglomeração tratados na economia regional do segundo bloco de definições, inspirou-se nas teorias marshalliana e keynesiana, a partir da década de 1950. Marshal (1930)

\footnotetext{
${ }^{4}$ Von Thünen (1826); Isard (1956); Hirschman (1958); North (1959) apud Monasterio e Cavalcante (2011).
} 
estabeleceu o conceito de distrito industrial, ao destacar as relações de aglomeração de empresas em um espaço. Com isso, foi evidenciada a possibilidade de economias externas de localização, no auxílio à diminuição dos custos de produção. A abordagem keynesiana também trouxe uma preocupação com esse tipo de economia e abordou o desenvolvimento, a partir do olhar de fora, com uma análise mais macro para curto prazo (MENDES; MATTEO, 2011).

Em 1950, ganhou destaque o mecanismo dinâmico de autorreforço, proveniente de fatores ligados à aglomeração industrial. Ao contrário dos clássicos, Perroux (1955) relatou que o crescimento não acontece homogeneamente no espaço e que se manifesta em polos de crescimento, com suas intensidades diversificadas e com efeitos variáveis, a depender da economia da região ou local.

Esses polos podem atuar de diferentes formas e as indústrias motrizes induziriam ao desenvolvimento regional, funcionando como uma espécie de polarização técnica, relacionada aos efeitos de encadeamento da indústria motriz, em relação às demais indústrias ou atividades; polarização econômica, no tocante à geração de emprego e renda; polarização psicológica sobre os investimentos gerados, a partir do otimismo dos benefícios que poderiam ser originados da indústria motriz e polarização geográfica associada à minimização dos custos, como os de transporte e a criação de economias externas e de aglomeração (MONASTÉRIO; CAVALCANTE, 2011).

O modelo conceitual de causação circular e cumulativa foi apresentado por Myrdal (1957), que relacionou a questão racial dos Estados Unidos com o folclore e com elementos bíblicos, indagando que haveria uma relação mútua de casualidade circular e cumulativa entre os fatores que impactam o desenvolvimento. Esse autor argumentou que a essência de um problema social envolve um complexo de mudanças interdependentes circulares e acumulativas, bem como a necessidade de considerar as diferentes formas de desenvolvimento e as desigualdades regionais.

Myrdal (1957) tentou expor que não existe uma autoestabilização no sistema social, pois ele não se move espontaneamente para um estado de equilíbrio, mas constantemente se afasta desse estado. Entretanto, mudanças não causam alterações compensatórias e, sim, conduzem o sistema, com mais intensidade na direção do objetivo inicial, sendo ele o equilíbrio e tornando o processo em acumulativo e cíclico. Logo, os fatores de produção, qualificação da mão-de-obra e a valorização do capital humano podem ser determinantes no desenvolvimento regional (MYRDAL, 1957).

Hirschman (1958), ao contrário de Myrdal (1957), identificou, na desigualdade, uma oportunidade ou uma condição necessária para realizar o processo de desenvolvimento, ou seja, o desenvolvimento seria obtido por meio de uma sucessão de desequilíbrios, que potencializariam os recursos escassos. No âmbito regional, o autor acrescentou os efeitos para frente (forward linkages), ligados à oferta de insumos, em que haveria setores se posicionando à jusante. $E$ os efeitos para trás (backward linkages), que expressam as externalidades resultantes da implementação de indústrias, com a viabilização das escalas mínimas de produção em uma região, por meio do aumento da demanda de insumos do setor à montante (MONASTÉRIO; CAVALCANTE, 2011).

Para North (1955), o desenvolvimento regional surgiu quando as exportações foram associados a fatores locacionais específicos, de modo a favorecer o surgimento de polos de distribuição nas cidades, que, por sua vez, geram indiretamente a demanda por serviços de exportação. Essas atividades ligadas ao mercado externo são denominadas por base exportadora. North (1955) sustentou ainda que a industrialização não garante que o desenvolvimento regional prossiga, mas o resultado do sucesso da base exportadora (MONASTÉRIO; CAVALCANTE, 2011).

Os pontos principais de cada estudo dentro do bloco relacionado à questão regional, com ênfase na aglomeração, proporcionam um suporte físico para as atividades econômicas e o entendimento das particularidades sociais. De acordo com Matteo (2011), o território deve ser analisado de forma integrada às relações sociais e econômicas, ao invés de serem apenas elementos externos.

Cabe destacar, nesse entendimento, o conceito de Arranjo Produtivo Local (APL), que também é contemplado nos aspectos de aglomeração e de desenvolvimento regional ou territorial. No entanto, vale ressaltar que, conforme Carleial (2011), esse termo é uma tropicalização do conceito do Sistema Regional de Inovação (SRI), que busca explicar, na distribuição localizacional, os impactos regionais das políticas das indústrias, o processo inovativo nas regióes de interesse, fundamentado na existência de uma base produtiva, e a interação de empresas, instituições e organizações socioeconômicas.

Ainda segundo Carleial (2011), esse sistema depende das economias de aglomeração, da capacidade de potencializar as externalidades produtivas e cooperação entre os agentes financeiros 
e institucionais. O termo APL acaba sendo generalizado e disseminado em diversos estudos, em que as identificações de aglomerações produtivas sejam denominadas como APL, fazendo com que este termo se demonstre como uma solução simples para estimular a atuação dos municípios e das entidades governamentais em políticas públicas. Esse termo apresenta alguns pontos negativos, como a ausência de visão regional, que ressalte as diferentes cadeias produtivas presentes na região e de mecanismos de monitoramento e aferição dos resultados das políticas públicas voltadas aos APLs.

Ao fim da década de 1980, apareceu, na literatura, a Nova Geografia Econômica (NGE), ramo que passou a analisar a distribuição no espaço das atividades econômicas, adicionando novos elementos da teoria do comércio internacional. Nesse sentido, novos conceitos de localização foram incorporados na estrutura de equilíbrio geral, fenômenos econômicos e as desigualdades regionais numa escala geográfica mais ampliada (CRUZ, 2011).

Neste estudo não será abordado o termo APL para as designações das atividades econômicas selecionadas como objeto de análise, contudo fez-se necessário abordar brevemente sobre o termo e identificar sua fragilidade, por se tratar de um termo muito utilizado em diversos textos de natureza científica semelhante a este estudo.

\section{Aspectos metodológicos: Indicadores de Especialização da Economia Regional}

Diversos autores utilizam a análise da economia regional, por meio de índices que possam explicar e demonstrar a importância de um setor, para uma região ou para o desenvolvimento local de um município. A construção desses indicadores possibilita verificar a distribuição geográfica dessas atividades, a fim de que se possa entender a interação regional dos setores avaliados, assim como discernir as especialidades regionais, que são resultantes dos processos de descentralização ou de concentração econômica da região analisada.

$\mathrm{O}$ indicador de desempenho econômico mostra a capacidade de geração de renda dessa economia e, com o auxílio de algumas outras informações, pode mostrar também o nível de utilização de sua capacidade produtiva (PAULANI; BRAGA, 2013, p. 336). Segundo Paulani e Braga (2013), a importância do bem-estar da sociedade, remete ao confronto entre as linhas dos conceitos de “crescimento econômico e desenvolvimento econômico". Para a mensuração de indicadores sociais, tem-se como base a condição socioeconômica de um país ou determinada região, inserida no contexto de crescimento e de desenvolvimento econômico.

Na literatura contemporânea, as abordagens em relação à economia industrial e à economia regional, segundo Crocco (2006), estão presentes na avaliação das características e contribuições de um determinado setor para o desenvolvimento local, regional e nacional. Crocco afirma, ainda, que existem outros trabalhos que utilizam outras metodologias, na tentativa de avaliar essas características, como os de Brito e Albuquerque (2002), Sebrae (2002), IEDI (2002) e Suzigan et al. (2003).

Os estudos de Brito e Albuquerque (2002) baseiam-se em alguns critérios, como no uso do Quociente Locacional (QL), que busca definir se o município da região estudada tem especialização ou não em alguma atividade específica. Crocco (2006) afirma que esses autores utilizam o QL para tentar comparar as estruturas setoriais e espaciais, caso esse índice seja maior ou igual a 1.

Segundo Paiva (2011), o Quociente Locacional tem como objetivo expressar a importância comparativa de um setor ou atividade produtiva em relação à região estudada, ao identificar quantas vezes uma determinada localidade se dedica a um setor específico. O QL é utilizado para mensurar o grau de relevância do nível de emprego de um setor ou atividade específica.

Já o trabalho do Sebrae (2002) segue a mesma linha de Brito e Albuquerque (2002), a diferença está na utilização da variável número de estabelecimentos e não número de empregos, para o cálculo do QL. No que tange aos trabalhos do Instituto de Estudo para o Desenvolvimento Industrial - IEDI - (2002) e de Suzigan et al. (2003), o método considera o cálculo de um Gini Locacional anterior à utilização do QL, como critério para a identificação de clusters ou sistemas produtivos locais (CROCCO et al, 2006).

Britto e Albuquerque (2002, p. 125), ao analisarem o quociente locacional em diversos níveis de agregação, chegaram a três considerações distintas:

a) Quando o $\mathrm{QL}=1$, a especialização do município $\mathrm{J}$ em atividades do setor i é idêntica à especialização do conjunto do Brasil nas atividades desse setor; 
b) Quando o QL < 1, a especialização do município j em atividades do setor i é inferior à especialização do conjunto do Brasil nas atividades desse setor;

c) Quando o QL > 1, a especialização do município j em atividades do setor é superior do conjunto do Brasil nas atividades desse setor.

Diante disso, admite-se que o QL é um indicador importante para a identificação da especialidade produtiva de uma região. A partir dele, pode ser encontrado o grau de concentração relativa de uma atividade ou setor em uma região ou município, bem como a participação dessa atividade na região estabelecida.

No entanto, em meio à desigualdade que existe no Brasil, o índice identifica, no mínimo, que um setor com QL acima de 1 pode deter uma diferenciação produtiva e não uma especialização do setor.

Conforme o estudo realizado por Rezende e Diniz (2013), a aplicação do índice deve ser cautelosa, porque, quando o indicador é utilizado em uma região pouco desenvolvida na questão industrial, pode haver um resultado elevado do nível de especialização de uma unidade produtiva, mesmo que não exista uma dimensão com alto nível de relevância.

O Índice Hirschman - Herfindahl - considera o modelo econômico de Cournot, que, tal qual Aleixo (2006), afirma que conceitua o comportamento de empresas, que decidem de maneira simultânea a quantidade a ser produzida e distribuída no mercado de atuação. Para tanto, são utilizadas informações de todas as empresas ou setores participantes do mercado. Embora o índice HH venha associado à Herfindahl (1950), sua paternidade pode ser atribuída a Hirschman que,

alguns anos antes (1945), utilizou a norma euclidiana do vetor das parcelas de mercado $(=\sqrt{H H})$ para medir a concentração industrial norte-americana (KUPFER, 2013).

Com o intuito de corrigir possíveis inconsistências no índice $\mathrm{HH}$, pelo fato do cálculo dos indicadores convencionais não refletirem, de maneira fidedigna, a situação de competição dos mercados ou dos setores, Bresnahan e Salop (1986) elaboraram um ajuste no índice, incluindo os efeitos das ligações estruturais existentes. $O$ índice passou a se chamar IHHM- índice de Hirschman e Herfindahl Modificado. O IHHM avalia a participação relativa para captar a relevância do setor ou atividade avaliada no estudo, por meio do nível de emprego ou remuneração salarial.

Havendo a necessidade de correção da deficiência do QL, foi desenvolvido o Índice de Concentração Normalizado, que utiliza três indicadores: Quociente Locacional (QL); o Índice de Hirschman e Herfindahl Modificado (IHHM) e o Índice de Participação Relativa (PR). Tais indicadores funcionam como elementos fundamentais para a construção de um único valor de concentração de uma atividade industrial, dentro de uma região. Esse índice único foi desenvolvido pelo Grupo de Pesquisa em Economia Regional e Urbana do CEDEPLAR (UFMG), no ano de 2003, organizado pelo pesquisador Marco Aurélio Crocco.

\section{Metodologia}

De modo a atender ao objetivo proposto, utilizou-se o método quantitativo de pesquisa, por meio das estimativas do Índice de Concentração Normalizado (ICN) para a bovinocultura de corte, avicultura e suinocultura de Mato Grosso do Sul. Para encontrar o ICN, foram calculados os índices de especialização: Quociente Locacional (QL); o Índice de Hirschman e Herfindahl Modificado (IHHM) e o Índice de Participação Relativa (PR).

Segundo Crocco et.al. (2003, 2006), o nível de especialização de uma região é identificado por quatro características: a) a especificidade de uma atividade dentro de uma região; b) o seu peso em relação à estrutura industrial da região; c) a importância do setor no âmbito nacional e d) a escala absoluta da estrutura industrial local.

Além disso, foi considerada a Classificação Nacional de Atividades Econômicas (CNAE), conforme descrito no quadro 1, para a extração dos dados secundários do Ministério do Trabalho e Emprego (MTE) sobre a Relação Anual de Informações Sociais - RAIS -, referente ao ano de 2016 (o mais atual disponível na plataforma). 
Quadro 1: Descrição das atividades pecuárias, de acordo com os CNAEs correspondentes

\begin{tabular}{|l|l|l|l|}
\hline ATIVIDADES & $\begin{array}{l}\text { ATIVIDADE } \\
\text { RELACIONADA }\end{array}$ & $\begin{array}{l}\text { CNAE } \\
\text { CORRESPONDENTE }\end{array}$ & ATIVIDADE \\
\hline Bovinos vivos & Criação & $0152-2$ & Criação de Bovinos \\
\hline $\begin{array}{l}\text { Abate de } \\
\text { bovinos }\end{array}$ & Indústria & $1011-2$ & $\begin{array}{l}\text { Abate de Reses, exceto } \\
\text { suínos }\end{array}$ \\
\hline Aves vivas & Criação & $0155-5$ & Criação de aves \\
\hline Abate de aves & Indústria & $1012-1 / 01$ & Abate de Aves \\
\hline Suínos vivos & Criação & $0154-7 / 00$ & Criação de suínos \\
\hline $\begin{array}{l}\text { Abate de } \\
\text { suínos }\end{array}$ & Indústria & $1012-1 / 03$ & $\begin{array}{l}\text { Frigorífico - abate de } \\
\text { suínos }\end{array}$ \\
\cline { 2 - 4 } & $1012-1 / 04$ & $\begin{array}{l}\text { Matadouro - abate de } \\
\text { suínos sob contrato }\end{array}$ \\
\hline
\end{tabular}

Fonte: Elaborado pelo autor.

Para calcular o QL, que teve por objetivo analisar a especificidade das atividades selecionadas, de acordo com a nomenclatura do CNAE, no estado do Mato Grosso do Sul, considerouse:

Em que:

$$
Q L=\frac{E_{j}^{i} / E_{j}}{E_{M S}^{i} / E_{M S}}
$$

$E_{j}^{i}=0$ emprego da suinocultura no município j;

$E_{j}=\mathrm{O}$ emprego em todos os setores do município j;

$E_{M S}^{i}=$ O emprego da suinocultura no estado de Mato Grosso do Sul;

Os autores Brito e Albuquerque (2002), Sebrae (2002), IEDI (2002) e Suzigan et al. (2003) atribuem ao QL um papel importante para determinar se um município tem especialização em uma atividade estipulada, neste caso de dados relativos a emprego. Detiveram nível de especialização, os resultados maiores que 1 (um).

Já no que se refere ao Indicador Hirschman e Herfindahl Modificado (IHHM), que captou o real peso da atividade analisada na estrutura produtiva, tem-se:

$$
I H H m=\left(\frac{E_{j}^{i}}{E_{M S}^{i}}\right)-\left(\frac{E_{j}}{E_{M S}}\right)
$$

Por fim, o indicador de Participação Relativa (PR), voltado à importância do município, em relação ao estado do Mato Grosso do Sul, foi descrito na equação 3. O valor de PR varia entre zero e um e, quanto mais próximo de um, maior será a importância do setor para o município.

$$
R=\left(\frac{E_{j}^{i}}{E_{M S}^{i}}\right)
$$

Após terem sido calculados o QL, IHHM e o PR, foi possível estimar o ICN, cuja mensuração ocorreu por meio da combinação linear dos componentes padronizados, como demonstrado na equação 4 . O ICN permitiu compreender a capacidade de representação das aglomerações.

$$
I C n_{i j=\theta_{1}} Q L n_{i j+\theta_{2}} P R n_{i j}+\theta_{3} H H n_{i j}
$$

$\theta=$ Peso de cada indicador para cada setor produtivo.

De acordo com Mingoti (2005, p. 59), "seu principal objetivo é o de explicar a estrutura de variância e covariância de um vetor aleatório, composto de p-variáveis aleatórias, através da construção de combinações lineares das variáveis originais.” Essas combinações lineares são 
chamadas de componentes principais e são não correlacionadas entre si. Se temos p-variáveis originais é possível obter p componentes principais. $\mathrm{Na}$ análise dos componentes principais, são tomadas " $\mathrm{n}$ " variáveis, para produzir componentes $\mathrm{Z}_{1}, \mathrm{Z}_{2}, . . \mathrm{Z}_{\mathrm{n}}$ :

$$
Z_{i}=a_{i 1} X_{1}+a_{i 2} X_{2}+\ldots+a_{i p} X_{p}
$$

Sujeita à condição:

$$
\mathrm{a}_{\mathrm{i} 1}^{2}+\mathrm{a}_{\mathrm{i} 2}^{2}+\ldots+\mathrm{a}_{\mathrm{ip}}{ }^{2}=1
$$

Por meio da matriz de variância simétrica (equação 7), identificou-se as variâcias relacionadas aos seus respectivos componentes e coeficientes das combinações lineares. As variâncias encontradas foram denominadas de componentes principais, os autovalores da matriz e ai1, ai2, ... aip de seus autovetores associados.

$$
\mathrm{C}=\left[\begin{array}{cccc}
c_{11} & c_{12} & \cdots & c_{1 p} \\
c_{21} & c_{22} & \cdots & c_{2 p} \\
\vdots & \vdots & \vdots & \vdots \\
c_{p 1} & c_{p 2} & \cdots & c_{p p}
\end{array}\right]
$$

Cabe destacar que a soma dos autovalores é igual à soma dos elementos da diagonal principal da matriz de covariância, ou seja, o traço da matriz:

$$
\lambda_{1}+\lambda_{2}+\lambda_{3}+\ldots+\lambda_{p}=c_{11}+c_{22}+\ldots+c_{\mathrm{pp}}
$$

Para garantir que o conjunto de todos os componentes considere a variação total de dados, Crocco (2003) afirma que uma vez que cii é a variância de $\mathrm{Xi}$, e $\lambda \mathrm{i}$ a dos $\mathrm{Zi}$, obtém-se a soma das variâncias de todas as variáveis originais, iguais aos componentes.

Para se obter os pesos das variáveis, por meio de componentes principais (PCA), foi utilizado o software estatístico STATA, que forneceu os autovalores dos componentes principais, por meio da matriz de correlação e a variâncias dos componentes, para o cálculo de cada variável.

Quadro 1: Autovalores da matriz de correlação ou variância explicada pelos componentes principais

\begin{tabular}{|l|l|l|}
\hline COMPONENTE & $\begin{array}{l}\text { VARIÂNCIA EXPLICADA } \\
\text { PELO COMPONENTE }\end{array}$ & $\begin{array}{l}\text { VARIÂNCIA } \\
\text { EXPLICADA TOTAL }\end{array}$ \\
\hline 1 & $\beta 1$ & $\beta 1$ \\
\hline 2 & $\beta 2$ & $\beta 1+\beta 2$ \\
\hline 3 & $\beta 3$ & $\beta 1+\beta 2+\beta 3(=100 \%)$ \\
\hline
\end{tabular}

O Quadro 3 apresenta a matriz de coeficientes que demonstrou o cálculo da participação relativa de cada um dos indicadores com seus respectivos componentes.

Quadro 2: Matriz de coeficientes ou autovetores da matriz de correlação

\begin{tabular}{|l|l|l|l|}
\hline $\begin{array}{l}\text { INDICADOR DE } \\
\text { INSUMO }\end{array}$ & COMPONENTE 1 & COMPONENTE 2 & COMPONENTE 3 \\
\hline $\mathrm{QL}$ & $\propto_{11}$ & $\propto_{12}$ & $\propto_{13}$ \\
\hline $\mathrm{PR}$ & $\propto_{21}$ & $\propto_{22}$ & $\propto_{23}$ \\
\hline $\mathrm{HHm}$ & $\propto_{31}$ & $\propto_{31}$ & $\alpha_{33}$ \\
\hline
\end{tabular}


O Quadro 4 mostra a participação relativa de cada índice, oriunda da matriz de auto vetores da matriz de correlação. Desse modo, a partir da soma da função módulo dos autovetores associados a cada componente, foram obtidos os Ci e, em seguida, o módulo de cada autovetor foi dividido pela soma (Ci) associada aos componentes.

Quadro 3: Matriz de autovetores recalculados ou participação relativa dos indicadores em cada componente

\begin{tabular}{|l|l|l|l|}
\hline INDICADOR & COMPONENTE 1 & COMPONENTE 2 & COMPONENTE 3 \\
\hline QL & $\alpha_{11}=\frac{\alpha_{11}}{C_{1}}$ & $\alpha_{12}=\frac{\alpha_{12}}{C_{2}}$ & $\alpha_{13}=\frac{\alpha_{13}}{C_{3}}$ \\
\hline $\mathrm{PR}$ & $\alpha_{21}=\frac{\alpha_{21}}{C_{1}}$ & $\alpha_{22}=\frac{\alpha_{22}}{C_{2}}$ & $\alpha_{23}=\frac{\alpha_{23}}{C_{3}}$ \\
\hline $\mathrm{HHm}$ & $\alpha_{31}=\frac{\alpha_{31}}{C_{1}}$ & $\alpha_{32}=\frac{\alpha_{32}}{C_{2}}$ & $\alpha_{33}=\frac{\alpha_{33}}{C_{3}}$ \\
\hline
\end{tabular}

Tendo em vista que os áij do Quadro 4 representam o peso que cada variável, que foi assumido dentro de cada componente e que os autovalores ( $\beta s$ do Quadro 1) fornecem a variância dos dados associada ao componente, o peso final de cada indicador foi o resultado da soma dos produtos dos áij pelo seu autovalor correspondente $(\beta)$ - para cada componente.

$$
\begin{aligned}
& \theta_{1}=\alpha_{11} \beta_{1}+\alpha_{12} \beta_{2}+\alpha_{13} \beta_{3} \\
& \theta_{2}=\alpha_{21} \beta_{1}+\alpha_{22} \beta_{2}+\alpha_{23} \beta_{3} \\
& \theta_{3}=\alpha_{31} \beta_{1}+\alpha_{32} \beta_{2}+\alpha_{33} \beta_{3}
\end{aligned}
$$

Em que:

$$
\begin{aligned}
& \theta_{1}=\text { Peso do } \mathrm{QL} ; \\
& \theta_{2}=\text { Peso do HHm; } \\
& \theta_{3}=\text { Peso do PR. }
\end{aligned}
$$

Após obter os pesos para cada variável, os resultados foram somados, de modo que, para chegar a um número índice, utilizou-se da combinação linear dos indicadores padronizados, na aplicação da equação do ICN. O critério de seleção do índice foi norteado pela premissa de que seu resultado apresente um grau maior que 1. Nessas circunstâncias, justificaria que o município poderia ser relevante na estrutura econômica da representação da cadeia produtiva analisada, ao deter um nível de especialidade da atividade ou setor, na região estudada. É importante acrescentar que as análises contemplaram uma série histórica, iniciada em 2006, tendo em vista que a partir desse período passou a ser utilizada a nomenclatura CNAE 2.0 classes.

\section{Resultados e Discussões}

\section{Desempenho dos setores da pecuária no Brasil e no Mato Grosso do Sul}

A pecuária tem uma participação significativa no mercado mundial, principalmente da bovinocultura de corte. No que se refere à suinocultura e à vicultura também são inegáveis os avanços produtivos. De acordo com o relatório Perfil da Pecuária no Brasil (ABIEC, 2017), foram produzidas em 2016, aproximadamente, 10 milhões de toneladas de carne bovina; desses, 20\% se voltaram ao mercado externo e $80 \%$ ao mercado interno. Já as carnes de frango e suína, nesse mesmo período, abasteceram $66 \%$ e $80,4 \%$ do mercado interno, $34 \%$ e $19,6 \%$ da produção foram voltados ao mercado externo, respectivamente (ABPA, 2017). 
Gráfico 1: Consumo per capita de Carne no Brasil (Kg/ Habitante/Ano)

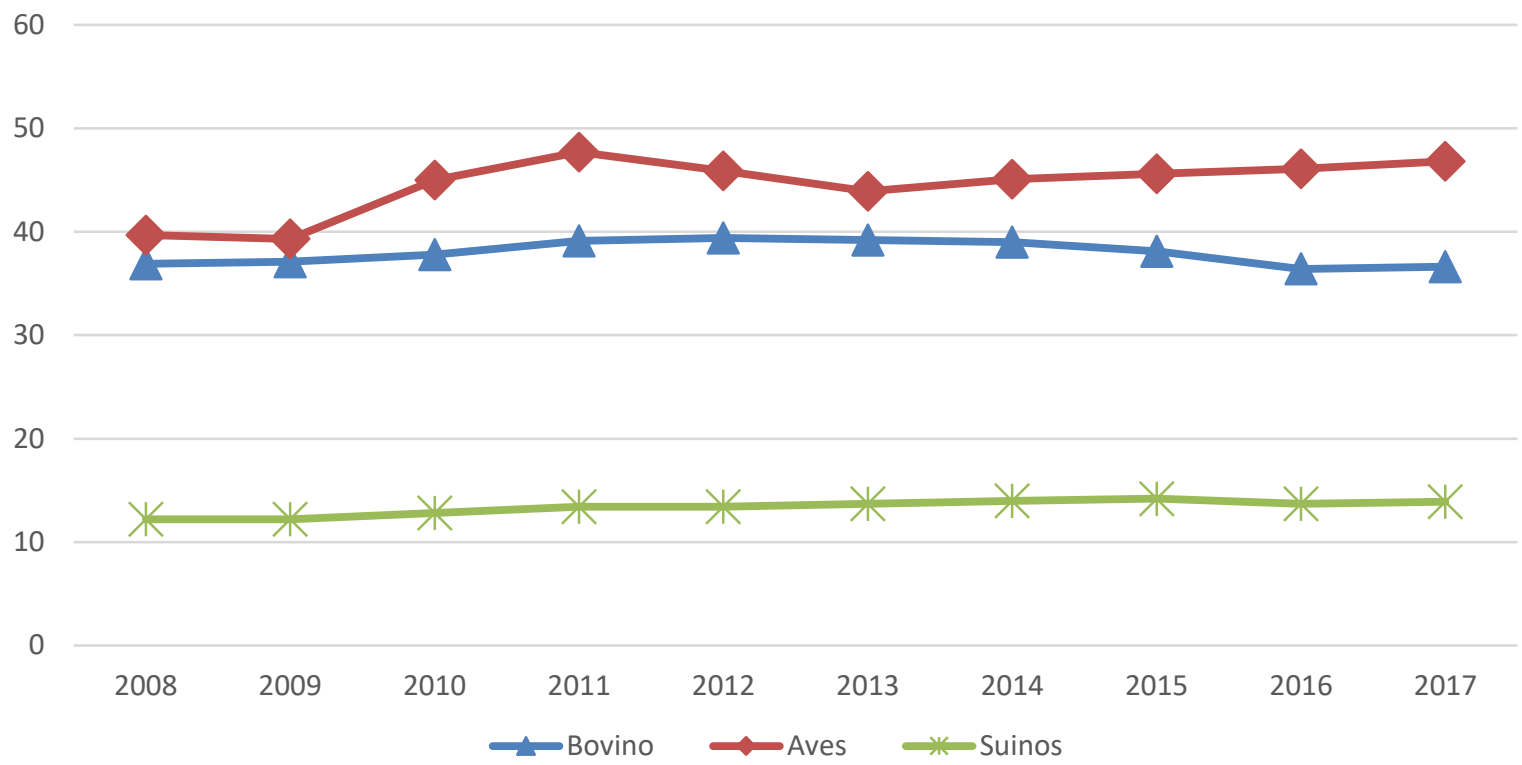

Fonte: Elaborado pelos autores com base nos dados USDA, 2017.

Os dados do USDA (2017) apontam que o consumo brasileiro da carne de frango tem superado o de carne bovina. Nos últimos anos, entretanto, a bovinocultura de corte se destacou não só na produção e no consumo nacional, mas também nas lideranças das exportações, o que beneficiou positivamente a balança comercial brasileira. 0 gráfico 2 apresenta a evolução da produção brasileira do mercado de carnes, do Brasil, de 2008 a 2017.

Assim como no Brasil, o Estado de Mato Grosso do Sul também caminhou positivamente para a ampliação de seu mercado e de sua participação no âmbito nacional. Segundo a FAMASUL (2017), as expectativas de crescimento, para os próximos anos, desse mercado são otimistas. Somente em 2018, a produção de carne bovina se aproximou de 791 milhões de toneladas; de carne de frango, houve um incremento de quase 3,9\% ( $+417,6$ toneladas) e de carne suína $7 \%$ (+144 toneladas). No caso da carne de frango, o volume exportado reduziu, devido ao embargo imposto às importações de carne de frango pela UE, durante o ano de 2018, de 20 frigoríficos do Brasil (PORTAL DO GOVERNO DO MS, 2018).

Gráfico 2: Produção Brasileira de Carnes (Bovina, Suína e de Frango)

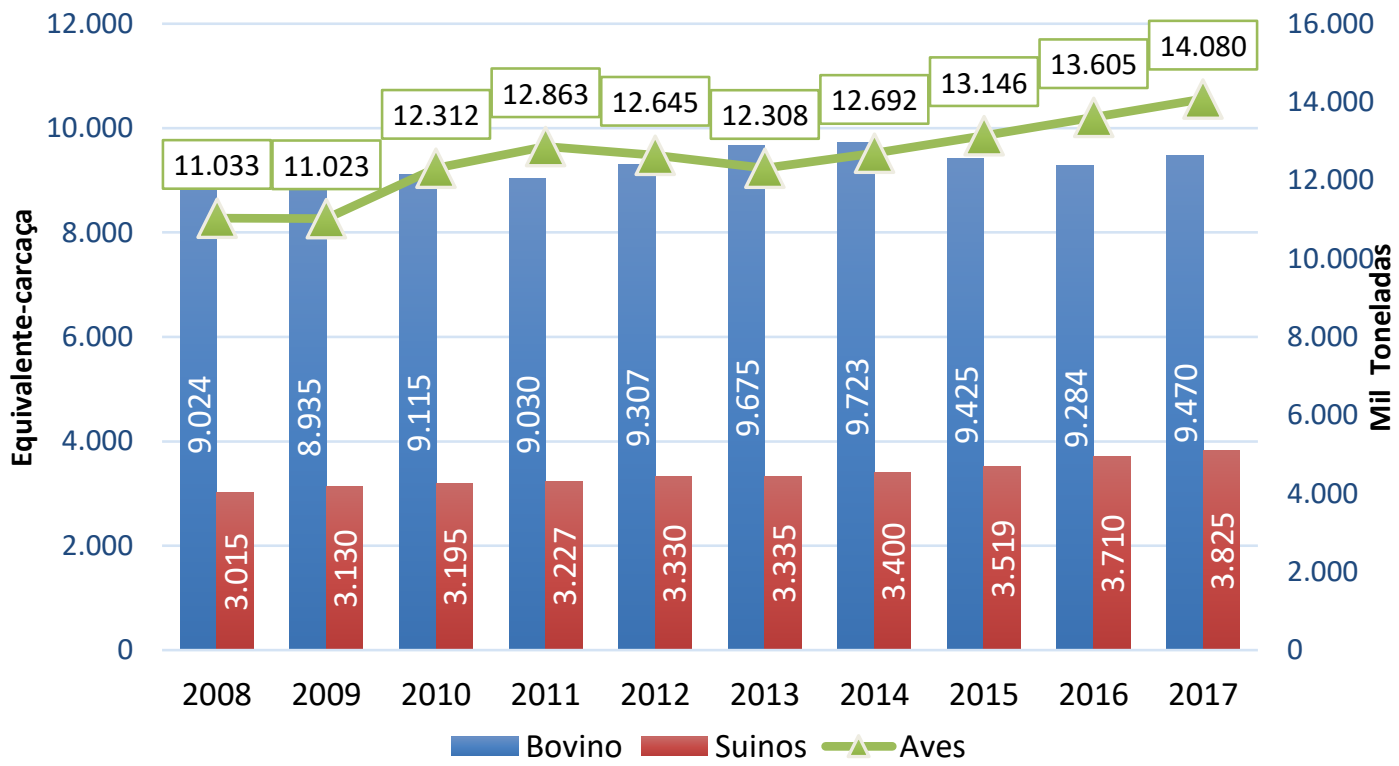

Fonte: Elaborado pelos autores com base nos dados USDA, 2017. 
Segundo o Balanço Anual do Agronegócio Sul-Mato-Grossense (2017), a suinocultura foi a atividade que mais se destacou nos últimos 17 anos, cresceu mais de $180 \%$, em função dos incentivos ao desenvolvimento da cadeia produtiva e dos avanços tecnológicos. A avicultura também teve um progresso relevante e alcançou um crescimento da produção de 141,11\%, para esse mesmo período. Já para a bovinocultura de corte, esse percentual foi de $20,87 \%$. Ao comparar as produções das atividades pecuárias, apesar desses percentuais de crescimento, o destaque em termos de volume coube à bovinocultura de corte.

Em 2017, no Mato Grosso do Sul, foram produzidas 417,6 mil toneladas de frango, um crescimento de $3,9 \%$, em relação a 2016. No caso da suinocultura, foram abatidas 144 mil toneladas de suínos, um aumento de $7 \%$, nesse mesmo período.

Os resultados da geração de empregos formais (ou número de pessoas ocupadas) também seguiram, em menores proporções, essas tendências de crescimento para a pecuária, que foram apresentadas nos gráficos 3 e 4, em conformidade com os dados do Ministério do Trabalho e Emprego (MTE).

Gráfico 3: Evolução do emprego formal no setor de criação

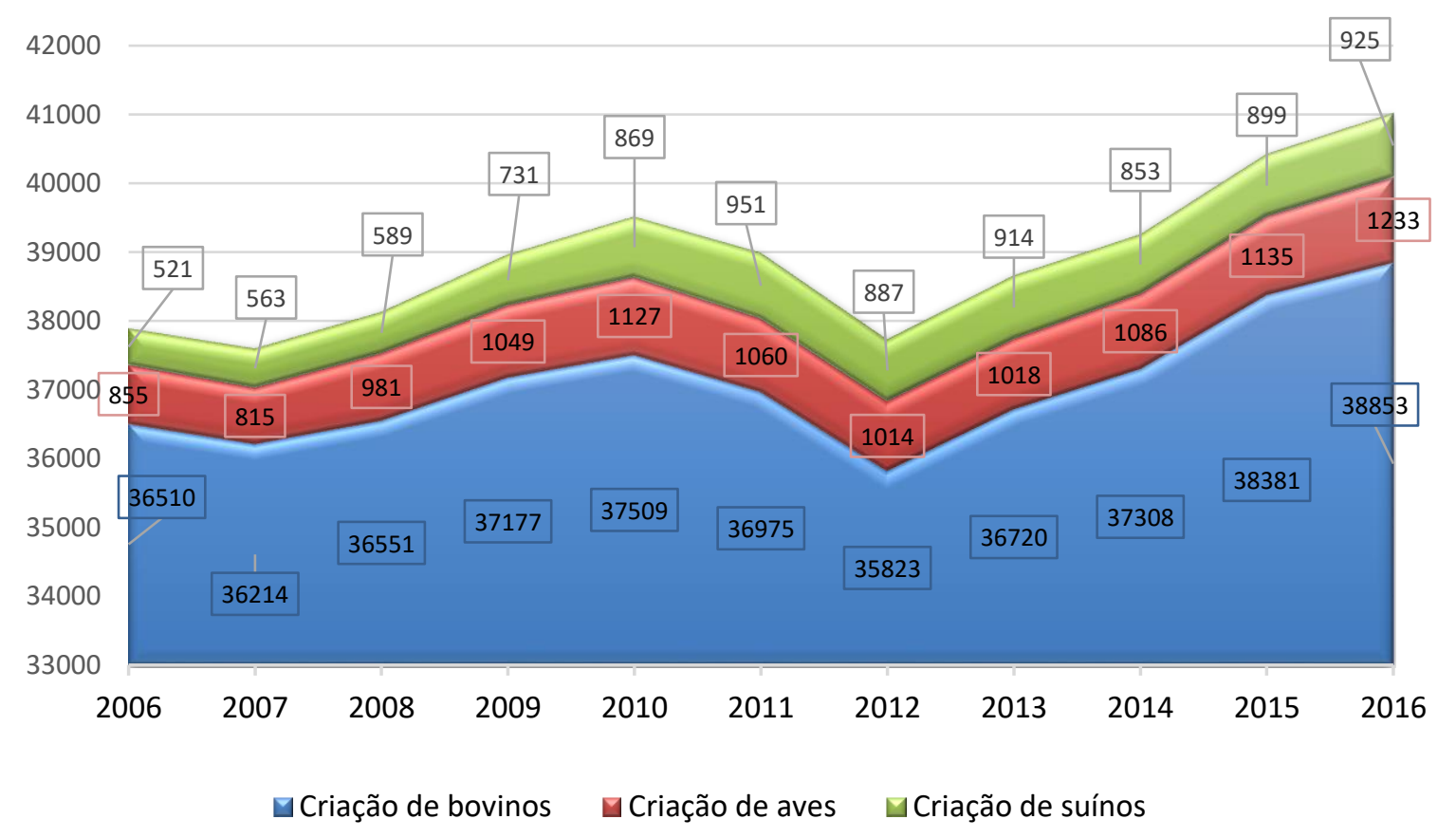

Fonte: Elaborado pelos autores com base nos dados da RAIS, 2017.

De 2006 a 2016, a criação de gado deteve um aumento de 6\%, de aves (frango), 44\%, e de suínos, $78 \%$ no efetivo de empregos com carteira assinada. Para os frigoríficos, esses percentuais foram, respectivamente, de $-13 \%, 44 \%$ e $107 \%$. Por esses resultados, observa-se que, apesar da representatividade da bovinocultura de corte em volume produzido e dos avanços da produtividade, essa atividade se tornou menos intensiva, com o passar dos anos, em mão-de-obra, na comparação à avicultura e à suinocultura. 
Gráfico 4: Evolução do emprego formal no setor na indústria frigorífica

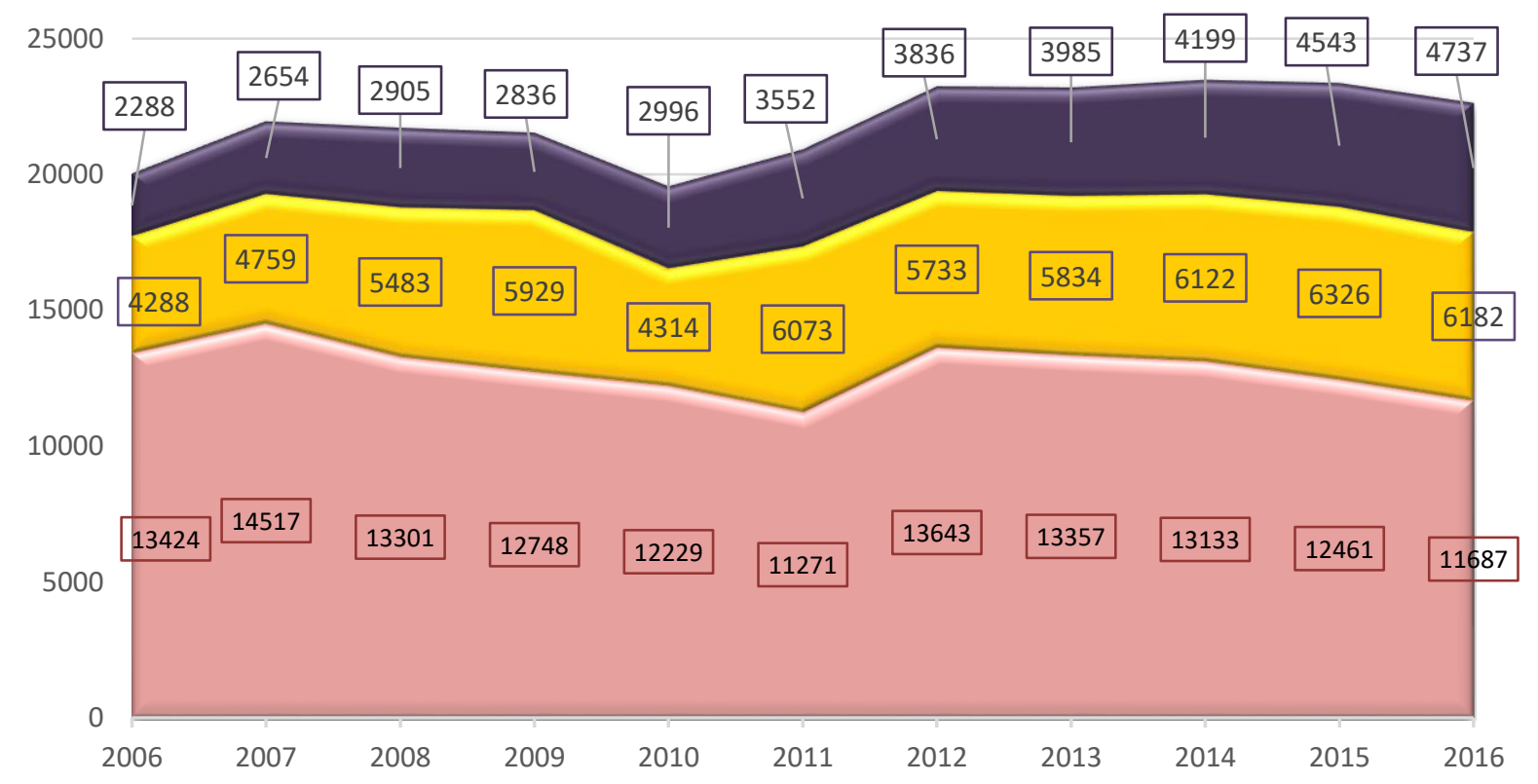

$\square$ Frigorífico - Abate de bovinos $\square$ Abate de aves $\square$ Frigorífico - Abate de suínos

Fonte: Elaborado pelos autores com base nos dados da RAIS, 2017.

As informações apresentadas neste tópico ressaltam a importância do setor da pecuária ao longo dos anos, enquanto um dos principais segmentos para a economia nos âmbitos nacional e estadual. Ao relacionar essa importância e comportamento dos resultados de produção e emprego com as aglomerações das atividades pecuárias, pode-se dizer que haveria oportunidades de potencializar ou auferir um maior nível de desenvolvimento regional. Isso ao considerar as estratégias para a otimização da localização das atividades e de alguns determinantes, como os tratados por Perroux (1955), Myrdal (1957) e Hirschman (1958), diante da existência de polos de crescimento de qualificação da mão-de-obra, em que a valorização do capital humano pode ser mensurada, por meio do cálculo do ICN do emprego formal, descrito no tópico seguinte.

\section{Índice de Concentração Normalizado no Emprego Formal}

Com a aplicação da metodologia proposta neste estudo, a partir de dados secundários disponíveis pelo Ministério do Trabalho e Emprego (MTE), foi possível identificar os municípios que apresentaram grau de especialização tanto na produção, quanto na indústria das atividades pecuárias de Mato Grosso do Sul, para o ano de 2016 (dados mais atualizados até então).

Na produção de bovinos, os municípios de Corumbá (1,2500), Porto Murtinho (1,5931), Ribas do Rio Pardo (1,7643) e Santa Rita do Pardo (1,4682) apresentaram os maiores níveis de concentração na geração de emprego formal. Como apresentado da Figura 1, diversas cidades não obtiveram um grau determinante maior que 1, mas tiveram níveis consideráveis para a criação de bovinos, índices esses que poderiam impactar indiretamente na pecuária ou mesmo poderiam ser consideradas como potencialidades futuras.

No que tange às indústrias, os destaques para o nível de concentração couberam a: Bataguassu (3,5354), Rochedo (2,5076), Nova Andradina (2,0536), Naviraí $(1,8030)$, Guia Lopes da Laguna $(1,0238)$ e Anastácio $(1,5931)$.

Cabe ressaltar que, em municípios cujo nível populacional é considerado pequeno, na comparação a regiões industriais, a instalação ou presença de indústrias podem fomentar o desenvolvimento econômico e regional. Além disso, a maioria dessas regiões industriais estão mais próximas da fronteira com outros estados, o que favorece o escoamento da produção e o acesso aos insumos. Com isso, estrategicamente, essa localização favorece a produtividade do setor e impacta na geração de empregos. 
As indústrias das regiões em destaque da Figura 1, que atuam com o Selo de Inspeção Federal, que podem ser consideradas como polos industriais e que em alguns casos estão próximas às fronteiras são: Marfrig Alimentos S.A, Minerva S.A., JBS S.A, Vale Grande Indústria e Comércio de Alimentos S.A., Mfb Marfrig Frigoríficos Brasil, Frigoríficos Mataboi S.A (ABIEC, 2016).

Fatores destacados na literatura por Mydral (1957) e Hirschman (1958) levam em consideração que os elementos relacionados à produção são determinantes para o desenvolvimento regional e para a valorização do capital humano, bem como para diminuição dos custos de produção. Uma vez que as questões sociais geram oportunidades que potencializam uma região, dadas as suas peculiaridades.

Figura 1: Índice de Concentração Normalizado para a Bovinocultura

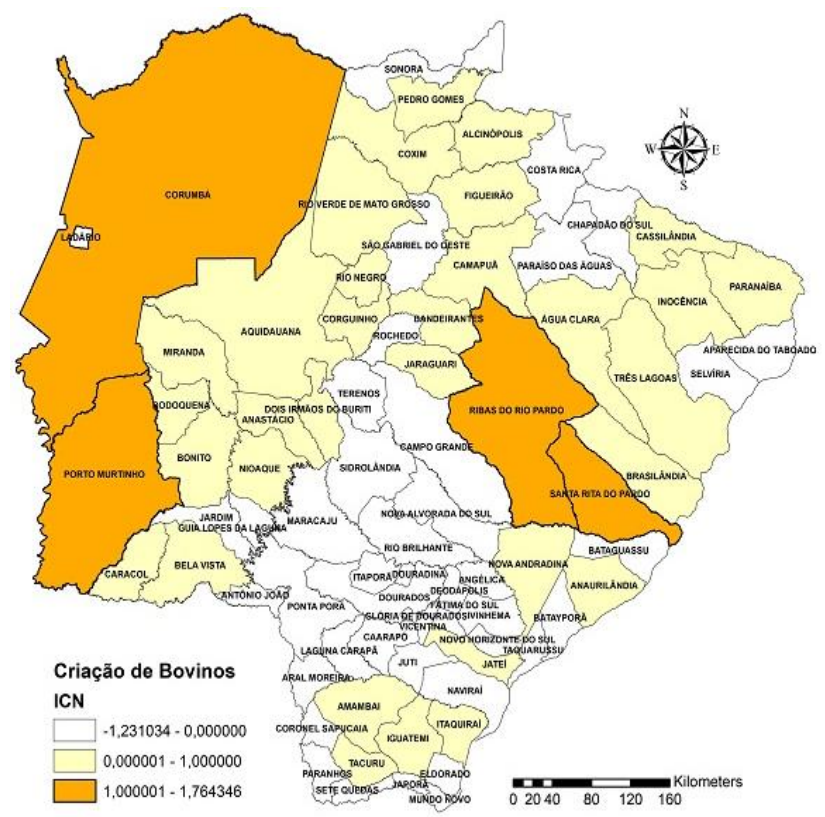

Tendo em vista a representatividade na bovinocultura de corte no Estado de Mato Grosso do Sul, o Governo do Estado, publicou o decreto n ${ }^{0}$ 14.772, no Diário Oficial do Estado do Mato Grosso do Sul, em 28 de junho de 2017, que permitiu a redução da alíquota do ICMS (Imposto Sobre Circulação de Mercadorias e Serviços) de $12 \%$ para $7 \%$ para a comercialização do boi em pé, fato que, de certa forma, também impactou nas negociações de aves e suínos.

Ainda segundo o Diário Oficial, essa medida demonstra o interesse do Estado não só pela indústria, mas também em reduzir a carga tributária nas operações interestaduais, de forma a estabelecer condições favoráveis para que os produtores rurais superem possíveis dificuldades do comércio local, devido à concentração empresarial na indústria frigorífica.

Além desse tipo de estímulo, vale destacar que o Mato Grosso do Sul se posiciona com um dos maiores produtores de milho e soja do Brasil, que são os principais insumos utilizados para a produção de rações que alimentam as aves (frango). Essa representatividade funciona como uma importante estratégia ou fator que possibilitou o estímulo à avicultura no estado.

$\mathrm{Na}$ produção de aves, os municípios que se destacaram no nível de concentração foram: Sidrolândia $(4,3358)$, Água Clara $(3,4966)$, Terenos $(3,6681)$, Cassilândia $(2,0822)$, Dourados $(1,5283)$. O Estado do Mato Grosso do Sul conta com 602 granjas de corte, 38 granjas de postura, 22 granjas matrizeiras e 5 incubatórios, segundo informações do IAGRO (2014). No setor da indústria relacionada ao abate de aves, houve ênfase para: Sidrolândia $(4,8870)$, Itaquirai $(4,8477)$, Dourados $(2,6181)$, Caarapó $(1,0277)$ e Aparecida do Taboado $(1,0692)$, conforme a Figura 2.

No setor da indústria, estão presentes: Seara Alimentos em Sidrolândia com a maior planta frigorífica, Frango Bello em Itaquirai e Aparecidada do Taboado, BRF Brasil situada em Dourados, Doux Frangosul - JBS - no município de Caarapó e Frango Ouro em Aparecidada do Taboado. Observa-se, a partir do avanço da avicultura, que houve contribuições desse setor para o aperfeiçoamento das técnicas de trabalho, inclusas na adoção de novas tecnologias e que impactaram na qualidade e oferta dos produtos. 
Figura 2: Índice de Concentração Normalizado para a Avicultura

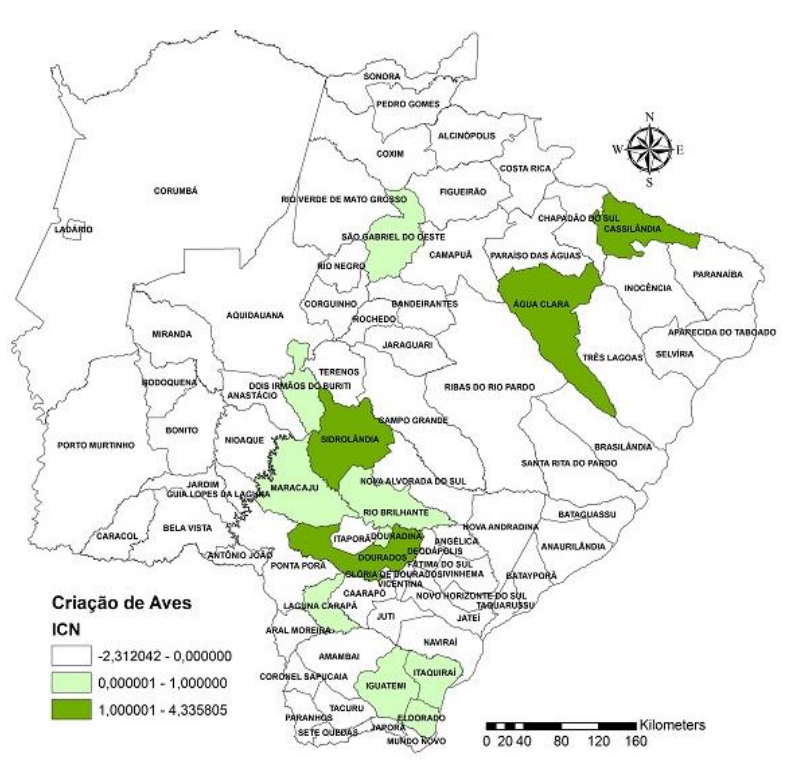

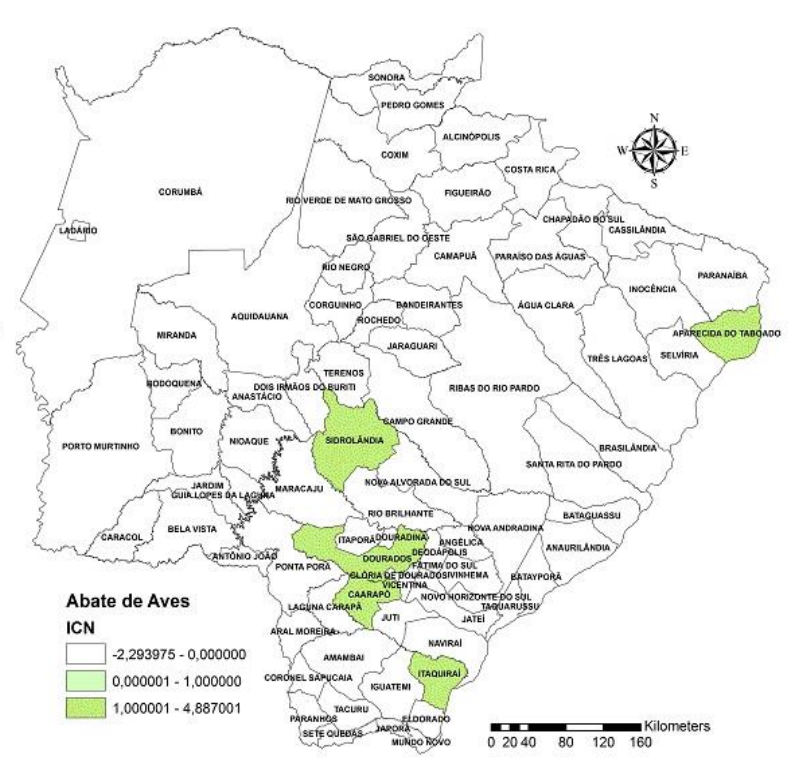

Fonte: Elaborado pelos autores.

A avicultura do estado está concentrada, principalmente na região centro-sul, funcionando como uma atividade $100 \%$ integrada, em que os elos de sua cadeia estão interligados e próximos às regiões onde estão localizadas as indústrias e os fornecedores de insumos, como em Dourados e São Gabriel do Oeste.

Essa atividade tende a diversificar a economia da região, proporcionando mais empregos, considerados tecnificados, para a melhoria no desempenho da produção. Segundo o relatório de produção animal da AviSite (2011), a avicultura se destaca em seu aspecto social, pela utilização de mão-de-obra intensiva e com isso conta com uma maior oferta de empregos diretos e indiretos e, consequentemente, com a arrecadação de tributos advindos da atividade.

A suinocultura acompanhou o crescimento das demais atividades, mas com menos expressividade. Os municípios que se destacaram na criação de suínos foram: São Gabriel do Oeste $(4,3253)$, Jateí $(4,1990)$, Ivinhema $(3,0076)$ e Vicentina $(1,3881)$, como demonstrado na Figura 3.

Algumas dessas cidades fazem parte da mesma região que tem maior concentração da produção avícola e, com isso, são utilizadas as mesmas estratégias de proximidades de onde os insumos são produzidos, o que justifica a aglomeração nessa localidade. De acordo com o Laboratório de Pesquisas Econômicas em Suinocultura (LAPESUL, 2015), 60\% da produção de suínos que abastece a agroindústria Aurora originam-se em São Gabriel do Oeste e cooperados da Cooasgo, que engloba produtores dependentes e independentes.

Dessa forma, quando se fala em indústria, há destaque para São Gabriel do Oeste $(5,7072)$ e Dourados $(5,1930)$, como apresentado na figura 3, a partir dos sistemas de produção cooperativo e integrado. A Cooasgo (de São Gabriel do Oeste) trabalha, principalmente, com a produção e a comercialização de suínos, entretanto também tem confinamento de Bovinos, Unidade Produtora de Leitão, UPL crechário.

Essa cooperativa atua no mercado da suinocultura com atividades da agropecuária, fornecendo suporte para a comercialização e para a produção de suínos, ao atender a demanda por matrizes, insumos, assistência técnica e armazenamento de grãos. É essa cooperativa que fornece produtos para a Indústria abatedoura Aurora. Em Dourados há maior domínio de mercado pela JBS - FOODS (SEARA) -, com seu sistema de integração, que fornece os principais mecanismos para a produção. 
Figura 3: Índice de Concentração Normalizado para a Suinocultura
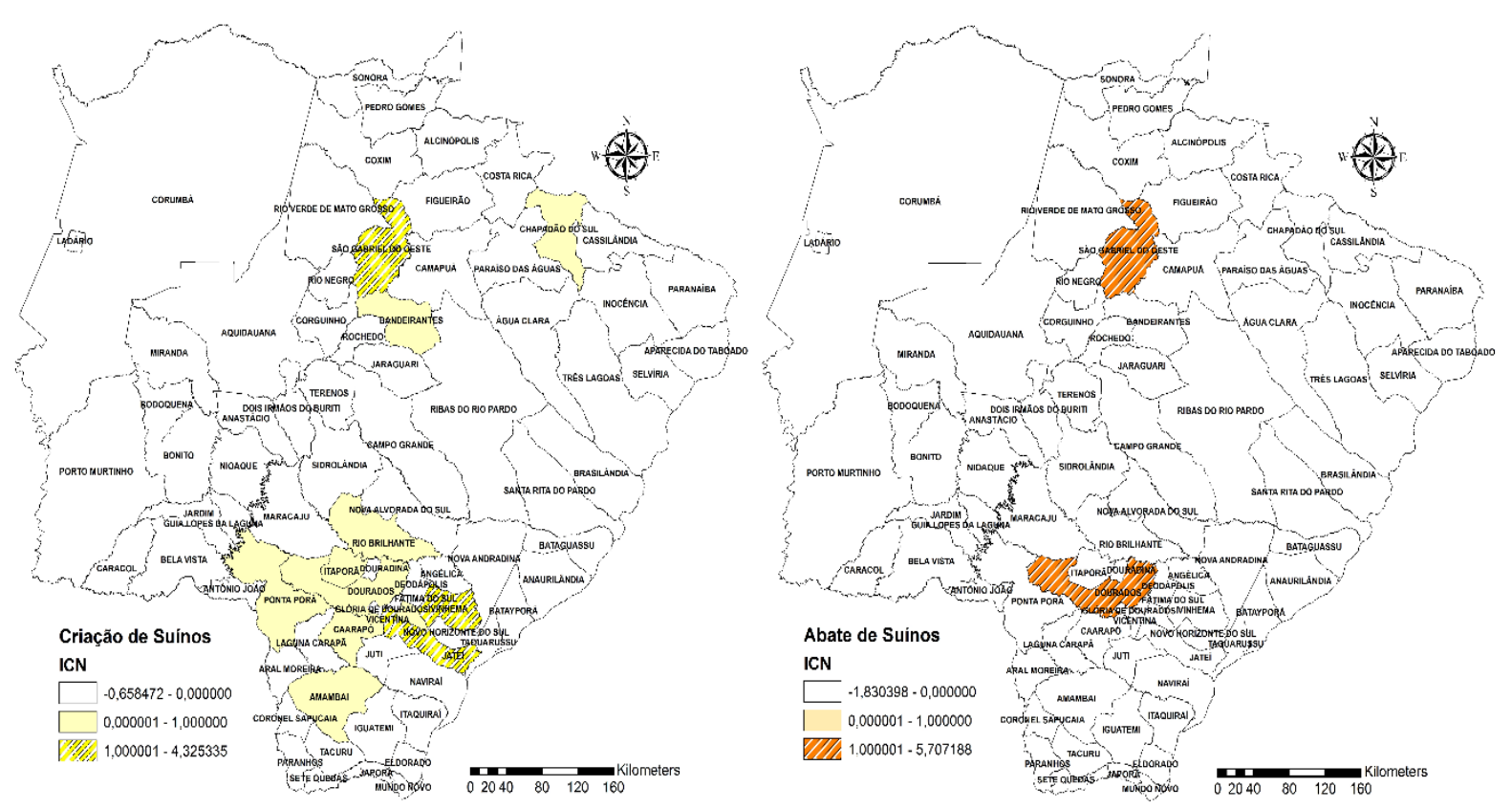

Fonte: Elaborado pelos autores.

O setor industrial da carne suína vem se caracterizando como um dos grandes responsáveis pela sustentação do desenvolvimento econômico e social de muitos municípios brasileiros, a partir da geração de empregos no campo, indústria, comércio e nos serviços (ABPA, 2013). A cadeia da suinocultura é complexa e envolve uma gama de empresas ligadas às várias etapas da produção até chegar ao consumidor final (ROSSI, PFÜLLER, 2008).

\section{Referências}

ABIEC, ASSOCIAÇÃO BRASILEIRA DAS INDÚSTRIAS EXPOTADORAS DE CARNE. Perfil da Pecuária no Brasil - Relatório Anual. p. 50, 2017. Disponível em: <http://www.abiec.com.br/PublicacoesLista.aspx>. Acesso em: 20 jan. 2018.

ALVES, F.D. Notas Teórico-Metodológicas entre Geografia Econômica e Desenvolvimento Regional. In: V Seminário Internacional sobre desenvolvimento regional. Rio Grande do Sul. 2011. Disponível em: <https://www.unifal-mg.edu.br/geres/files/unisc.pdf>. Acesso em: 18 maio 2020.

Pecuária Brasileira. Disponível em: <http://www.abiec.com.br/3_pecuaria.asp >. Acesso em: 15 jan. 2018.

ALEIXO, R. Os modelos de Cournot para duopólio e cartéis: uma revisão. IMECC, UNICAMP, Campinas, SP. 2006. Disponível em: <http://www.ime.unicamp.br/rel_pesq/2006/pdf/rp35-06.pdf>. Acesso em: 20 jan. 2018.

BRASIL. DECRETO No 14.772, DE 28 DE JUNHO DE 2011. Diário Oficial do Mato Grosso do Sul. Campo Grande - MS, jun 2017. Disponível em: < http://www.spdo.ms.gov.br/diariodoe/Index/Download/D09440_30_06_2017>. Acesso em: 15 jul. 2018.

BRESNAHAN, T. F. SALOP, S. C. Quantifying the competitive effects of production joint ventures. International Journal of Industrial Organization 4(2), 1986. 155-175.

BRITTO, J.; ALBUQUERQUE, E. M. Clusters industriais na economia brasileira: uma análise exploratória a partir de dados da RAIS. Estudos Econômicos, São Paulo, v.32, n.1, p. 71 - 102, 2002. 
CARLEIAL, L. A Contribuição Neoschumpeteriana e o Desenvolvimento Regional. In: CRUZ, B. O. et al. (Org.). Economia regional e urbana: teorias e métodos com ênfase no Brasil. Brasília: Ipea, 2011.

CEPEA, Centro de Estudos Avançados em Economia Aplicada. Boletim Cepea do Agronegócio Brasileiro. Piracicaba, v. 1, n.6, 2017. Disponível em: <https://www.cepea.esalq.usp.br/upload/kceditor/files/relatorio\%20pibagro\%20brasil_novembro_c epea.pdf >. Acesso em: 20 fev. 2018.

2017.

. Boletim PIB do agronegócio do Agronegócio Brasileiro. PIRACICABA, v. 1, n. 6, p. 5,

. PIB-AGRO/CEPEA: PIB-volume do agronegócio cresce 7,6\% em 2017, eleva PIB nacional e ajuda no controle da inflação. 2018. Disponível em: $<$ https://www.cepea.esalq.usp.br/br/releases/pib-agro-cepea-pib-volume-do-agronegocio-cresce

-7-6-em-2017-eleva-pib-nacional-e-ajuda-no-controle-da-inflacao.aspx >. Acesso em: 10 mar. 2018.

Mercado de Trabalho do Agronegócio Brasileiro. CEPEA - CENTRO DE ESTUDOS AVANÇADOS EM ECONOMIA, v. 1, n. 1, p. 7, 2018.

CROCCO, M. A.; GALINARI, R.; SANTOS, F.; LEMOS, M. B.; SIMÕES, R. Metodologia de identificação de arranjos produtivos locais potenciais: uma nota técnica. Belo Horizonte: UFMG/ CEDEPLAR, 2003. (Texto para Discussão, 191). Disponível em: <http://cedeplar.ufmg.br/pesquisas/td/TD\%20212.pdf>. Acesso em: 10 mar. 2018.

CROCCO, M. A., GALINARI, R., SANTOS, F., LEMOS, M. B. \& SIMÕES, R. (2006). Metodologia de identificação de aglomerações produtivas locais. Nova Economia 16(2), 211-241.

CRUZ, B.O. Uma Breve Incursão em Aspectos Regionais da Nova Geografia Econômica. In: CRUZ, B. O. et al. (Org.). Economia regional e urbana: teorias e métodos com ênfase no Brasil. Brasília: Ipea, 2011.

FAMASUL, FEDERAÇÃo DA AGRICULTURA E PECUÁRIA DE MATO GROSSO DO SUL. Balanço Sistema FAMASUL. 2017. Disponível em: <http://portal.sistemafamasul.com.br/producaode-graos-e-de-carne-bovina-de-ms-cresce-em-2017-mas-precos-baixos-diminuem-rentabilidadedo-produtor/>. Acesso em: 18 mar. 2018.

Infoagro Balanço Anual do Agronegócio Sul-Mato-Grossense 2015-2016. Senar/ MS e FAMASUL- Campo Grande -MS. 2017. Disponível em: < https://issuu.com/famasul/docs/infoagrosenar-2015-2016-web>. Acesso em: 18 mar. 2018.

IAGRO, Agência Estadual de Defesa Sanitária Animal e Vegetal. Frigoríficos. Disponível em: <http://www.iagro.ms.gov.br/tag/frigorifico/>. Acesso em: 20 fev. 2018.

HIRSCHMAN, A. O. Estratégia do desenvolvimento econômico. Rio de janeiro: Fundo de Cultura, 1961. 322 p. Disponível em: <https://ria.ufrn.br/jspui/handle/123456789/804>. Acesso em: 18 mai. 2020.

ISARD, W. Location and space economy: a general theory relation to industrial location, market areas, land use trade and urban structure. Cambridge: MIT Press, 1956.

KUPFER, D. HASENCLEVER, L. Economia Industrial - Fundamentos teóricos e práticas no Brasil. $2^{\mathrm{a}}$ edição. Elsevier. 2013.

MARSHALL, A. Princípios de economia. Madrid: Editorial Aguilar, 1930. 
MINGOTI, S. A. Análise de dados através de métodos de estatística multivariada: uma abordagem aplicada - Belo Horizonte. Editora UFMG, 2005.

MATTEO, M. Teorias de Desenvolvimento Territorial. In: CRUZ, B. O. et al. (Org.). Economia regional e urbana: teorias e métodos com ênfase no Brasil. Brasília: Ipea, 2011.

MINISTÉRIO DO TRABALHO (MTE). O que é a relação anual de informações sociais - RAIS. Disponível em: http://pdet.mte.gov.br/rais. Acesso em 10 mar. 2018.

MONASTERIO, L.; CAVALCANTE, L. R. Fundamentos do pensamento econômico regional. In: CRUZ, B. O. et al. (Org.). Economia regional e urbana: teorias e métodos com ênfase no Brasil. Brasília: Ipea, 2011.

MYRDAL, G. Teoria Econômica e Regiões Subdesenvolvidas. Rio de Janeiro. Editora Saga. 1957. $3^{\circ}$ Edição. $1972 . \quad$ Disponível em: <https://edisciplinas.usp.br/pluginfile.php/4425511/mod_resource/content/1/myrdal\%20gunnar\%2 $0 \% 28$ teoria $\% 20$ economica $\% 20 \mathrm{e} \% 20$ regioes $\% 20$ subdesenvolvidas $\% 29 \% 20$ cap $\% 202$.pdf $>$. Acesso em: 18 mai. 2020.

NETTO, A.D. Como as nações se desenvolvem? FGV. Revista Conjuntura Econômica. V. 53, n.5, 1999. Disponível em: <http://bibliotecadigital.fgv.br/ojs/index.php/rce/article/view/32886>. Acesso em: 12 jan. 2018.

NORTH, D. Agriculture in Regional Economic Growth. Journal of Farm Economics, v. 41, n. 5, p. 943-951, 1959.

PAIVA, C.A. Desenvolvimento regional, especialização e suas medidas. NERU. 2011. Disponível em: <http://cdn.fee.tche.br/indicadores/34_01/11_parte.pdf>. Acesso em: 15 mar. 2018.

PAULANI, L.M. BRAGA, M.B. A Nova Contabilidade Social - Uma nova introdução à macroeconomia. $4^{\text {a }}$ edição. Saraiva. 2013.

PERROUX, F. O conceito de pólo de desenvolvimento. In: SCHWARTZMAN, J. (Org.). Economia regional: textos escolhidos. Belo Horizonte: Cedeplar, p.145-156, 1977.

PORTAL DO GOVERNO DO MS. MS acompanha tratativas sobre embargo da União Europeia a frigoríficos de frango do País. Campo Grande- MS. 2018. Disponível em: <http://www.ms.gov.br/governo-acompanha-tratativas-sobre-embargo-da-uniao-europeia-a-doisfrigorificos-do-estado/>. Acesso em: 15 jul. 2018.

/REZENDE, A.C. DINIZ. B.P.C. Identificação de clusters industriais: uma aplicação de índices de especialização e concentração, e algumas considerações. Redes-Revista de Desenvolvimento Regional. Santa Cruz do Sul. V.18. p.38-54. 2013. Disponível em: <file:///C:/Users/User/Downloads/1507-16362-1-PB.pdf>. Acesso em: 20 jan. 2018.

SANTOS, E.L. BRAGA, V. SANTOS, R.S. BRAGA, A.M.S. Desenvolvimento: Um Conceito Multidimensional. DRD- Desenvolvimento Regional em debate. Ano 2, n.1. 2012. Disponível em: <https://dialnet.unirioja.es/descarga/articulo/5443930.pdf>. Acesso em: 08 jan.2018.

SEBRAE. Subsídios para a identificação de clusters no Brasil. Dez. 2002. Disponível em: $<$ http://bibliotecadigital.puc-campinas.edu.br/services/e-books/clusters_brasil.pdf >. Acesso em: 08 jan. 2018.

SEMADE. Diagnóstico Socioeconômico de Mato Grosso do Sul - 2015. SEMADE - Secretaria de Estado de Meio Ambiente e Desenvolvimento Econômico, p. 135, 2015.

VIEIRA FILHO, J. E. R.; SOUZA JÚNIOR, J. R. DE C. Carta de Conjuntura - Economia Agrícola. IPEA, v. 38, n. $1^{\circ}$ Trimestre de 2018, p. 1-32, 2018. 
SCHUMPETER, J. A. The Theory of Economic Development. Cambridge. Harvard University. 1957.

SUZIGAN, W. (Coord.). Identificação, mapeamento e caracterização estrutural de arranjos produtivos locais no Brasil. Instituto de pesquisa Econômica Aplicada - IPEA, Diretoria ide Estudos Setoriais, out. 2006.

USDA. ANUALPEC-Anuário estatístico da pecuária de corte. São Paulo: FNP Consultoria e Comércio Ltda., 2017.

VALOR ECONÔMICO. UE publica embargo a 20 frigoríficos de carne de frango do Brasil. São Paulo. 2018. Disponível em: <https://www.valor.com.br/agro/5523143/ue-publica-embargo-20frigorificos-de-carne-de-frango-do-brasil>. Acesso em: 15 jul. 2018.

Esta obra está licenciada com uma Licença Creative Commons Atribuição 4.0 Internacional. 